\title{
VERDADE E SIGNIFICADO NA TEORIA DOS ATOS DE FALA: notas sobre os pressupostos da teoria se- arleana
}

\author{
Filipe Almeida Gomes \\ (PUC-MG) \\ https://orcid.org/0000-0001-7356-3128 \\ Hugo Mari \\ (PUC-MG) \\ https://orcid.org/0000-0002-6267-1542
}

\section{RESUMO}

Desde sua formulação na primeira metade do século XX (AUSTIN, 1962), a Teoria dos Atos de Fala tem se consolidado como uma frutífera abordagem para a compreensão das relações entre língua(gem) e ação. Em favor dessa afirmação, podemos observar, por exemplo, o constante tratamento da teoria nos mais variados manuais linguísticos sobre Pragmática. Tendo em mente, pois, esse lugar privilegiado que, a despeito de seus críticos, a teoria alcançou, e com vistas a possibilitar novas incursões na Teoria dos Atos de Fala ou, até mesmo, em toda a filosofia da linguagem e da mente de John Searle, o presente artigo visa jogar luz sobre os conceitos de "significado" e "verdade" que subjazem à Teoria dos Atos de Fala de orientação searleana. Para tal, além de colocações pontuais decorrentes do conjunto de escritos do próprio John Searle, recuperamos as considerações de Mari (1998), Strawson (1982) e Walker (1997). Ao fim, sustentamos que na base da Teoria dos Atos de Fala está tanto a concepção da "verdade como correspondência" quanto o entendimento de que o significado é o produto das complexas relações entre o significado convencional da sentença (aspecto formal), por um lado, e o significado intencional do falante, enunciador (aspecto enunciativo), por outro.

PALAVRAS-CHAVE: Verdade; Significado; Atos de Fala; John Searle. 


\section{TRUTH AND MEANING IN THE SPEECH ACTS THEORY: notes on the assumptions of the Searlean theory}

\section{ABSTRACT}

Since its formulation in the first half of the twentieth century (AUSTIN, 1962), the Speech Acts Theory has been consolidated as a fruitful approach to understanding the relations between language and action. In this sense, we can observe, for example, the constant treatment of theory in the most varied language manuals on Pragmatics. Therefore, keeping in mind this privileged place that the theory has reached, despite its critics, and in order to make possible new incursions in the Speech Acts Theory or even in the whole John Searle's philosophy of language and mind, the present article aims to shed light on the concepts of "meaning" and "truth" that underlie Speech Acts Theory of Searlean orientation. To this end, in addition to punctual statements by John Searle, we recall the considerations of Mari (1998), Strawson (1982) and Walker (1997). In conclusion, we maintain that at the basis of the Speech Acts Theory lies both the "correspondence theory of truth" and the understanding that meaning is the product of the complex relationships between the sentence's conventional meaning (formal aspect) and the speaker's intentional meaning (real aspect). KEYWORDS: Truth. Meaning; Speech Acts; John Searle.

\section{Considerações iniciais}

“[...], pois muitas vezes o que é importante não é o que o filósofo disse, mas o que ele considera tão óbvio que não precisa de ser dito.”

(SEARLE, 1999, p. 8).

Constante e controversamente considerado o herdeiro do trono teórico do filósofo britânico J. L. Austin, o também filósofo (porém, ame- 
ricano) John Searle é um dos estudiosos que mais devotou sua vida e, consequentemente, sua carreira acadêmica à construção e ao esclarecimento das formulações teóricas da denominada Teoria dos Atos de Fala. Profícuo pensador, com diversas publicações abordando os mais variados temas, como cognição, educação, filosofia da linguagem, filosofia da mente, inteligência artificial, etc., Searle assume que sua filosofia é marcadamente adepta da visão iluminista em contraposição à escola filosófica pós-moderna (cf. SEARLE, 2000); daí, inclusive, seu extenso debate com Derrida, por exemplo.

E é partindo dessa rejeição de Searle ao ponto de vista pós-moderno que queremos, no decorrer deste artigo, evidenciar a concepção de "verdade" e a concepção de "significado" que subjazem à Teoria dos Atos de Fala, de acordo com a formulação do filósofo de Berkeley. Como pode ser observado em suas obras relacionadas especificamente à Teoria dos Atos de Fala (SEARLE, 1981; 2002a), tais concepções não estão explicitamente marcadas. Contudo, nos escritos searleanos cuja abordagem das questões linguísticas está relacionada a temas gerais como educação e sociedade, tais concepções recebem defesas mais claras e, em alguns momentos, robustas. Assim sendo, para além do que se possa extrair das afirmações que o próprio Searle destaca em diversos de seus textos, tomamos como base para essa discussão os comentários de Mari (1998), Strawson (1982) e Walker (1997) que, de algum modo, estão relacionados às concepções basilares da teoria searleana.

\section{Sobre a verdade}

[...] há por aí muitas teorias da verdade; mas quem quiser colocar a tradição em causa tem de atacar a teoria da verdade como correspondência. A teoria da verdade como correspondência é a norma, a posição de partida; as outras posições definem-se em relação a ela.

(SEARLE, 1999, p. 8).

Embora a questão da linguagem tenha se destacado como epicentro do debate filosófico nos últimos dois séculos, considerações de natureza similar - algo que poderíamos considerar um protótipo das discussões modernas - já são feitas, ao menos, desde a Grécia Antiga. Em Crátilo, por exemplo, Platão traz à luz o diálogo - entre Crátilo, Hermógenes e Sócrates - sobre qual seria a relação entre as palavras e as coisas. Mesmo nesse 
texto, que muitos sugerem ser o mais antigo tratado, da cultura ocidental, sobre a linguagem, já é possível perceber que para se tratar da linguagem humana dois conceitos são imprescindíveis: verdade e significado.

No tocante à noção de verdade, destacam-se ao menos cinco propostas teóricas: a Teoria da Verdade como Correspondência, a Teoria da Verdade por Coerência, a Teoria Pragmática da Verdade, a Teoria da Verdade por Redundância e a Teoria Semântica da Verdade. Deve-se ressaltar que, a depender da teoria, há uma preferência por expressões distintas ao termo "verdade", como é o caso da teoria coerentista, que usualmente opta pelo termo "validade", e da teoria pragmática, cuja preferência é pelo termo "veracidade". Além disso, é importante sublinhar que não há um consenso último acerca dos contrastes entre tais teorias, de modo que, para alguns, a Teoria da Verdade por Coerência, por exemplo, é apenas uma subclasse da Teoria da Verdade por Correspondência. Nesse sentido, tendo em vista que o debate linguístico-filosófico acerca da questão da verdade é demasiado amplo, não nos deteremos aqui a explicar a argumentação subjacente a todas as teorias da verdade mencionadas, e nem mesmo direcionaremos nossos esforços para estabelecer as distinções entre as teorias mais próximas. Nosso olhar estará posto apenas sobre a Teoria da Verdade como Correspondência, tomada por Searle como sendo uma de nossas posições-padrão, isto é, “opiniões que temos antes da reflexão, de modo que qualquer desvio delas exige um esforço consciente e um argumento convincente." (2000, p. 18) ${ }^{2}$.

A Teoria da Verdade como Correspondência, até onde se sabe, é a primeira das formulações teóricas acerca do conceito de verdade, tendo seus primeiros registros na obra de Platão - seja nos implícitos de Crátilo ou nos de Sofista. Contudo, sua sistematização tem sido, com razão, atribuída a Aristóteles, tanto por afirmar no capítulo VII do livro Gama de sua obra Metafísica que “dizer do que é, que ele é, e do que não é, que ele não é, é dizer o verdadeiro; dizer do que é, que ele não é, e do que não é, que ele é, é dizer o falso", quanto por sua colocação na obra Categorias:

Se, com efeito, o homem existe, a proposição pela qual nós dizemos que o homem existe é verdadeira; e, reciprocamente, se a proposição pela qual nós dizemos que o homem existe é verdadeira, o homem existe. Contudo, a proposição verdadeira não é de modo algum causa da existência da coisa; ao contrário, é a coisa que parece ser, de algum

2 Ressalte-se, aqui, que Searle (2000) sugere não confundir "posições-padrão" como "senso comum". 
modo, a causa da verdade da proposição, pois é da existência da coisa ou da sua não existência que dependem a verdade ou a falsidade da proposição. (ARISTÓTELES, 14b 16-23).

A teoria acerca da verdade conforme sistematizada por Aristóteles parece ser a mais intuitiva dentre as teorias da verdade. Talvez seja devido a esse caráter intuitivo, inclusive, que a Teoria da Verdade como Correspondência surja como sendo a mais disseminada das teorias da verdade ${ }^{3}$, tendo sido objeto de reflexão de importantes pensadores como Agostinho, Tomás de Aquino, René Descartes, Leibniz, Kant e, mais recentemente, John Searle - sem citar a já mencionada tríade grega ${ }^{4}$.

Em seu texto Theories of Truth, Ralph Walker discorre sobre a Teoria da Verdade como Correspondência afirmando que

Como uma explicação sobre aquilo em que consiste a verdade, ela sustenta que a verdade de $p$ consiste numa relação de correspondência entre $p$ e os fatos. Sustenta também que, se esta relação é obtida ou não, um fato existe. Não consiste em nada mais. Em particular, então, não consiste na correspondência de " $p$ corresponde aos fatos" com os fatos. (1997, p. 318, tradução nossa ${ }^{5}$ ).

Observemos que, conforme sinaliza Walker, esta abordagem não diz respeito àquilo que se convencionou chamar de "fatos brutos" (realidade), uma vez que estes apenas existem, sem estarem sob julgamento de serem verdadeiros ou falsos. Para o autor, a questão posta pela teoria diz respeito a uma adequação entre os fatos do mundo e as suas formas de representação. Nas palavras de Searle, “a ideia básica é que as afirmações são verdadeiras

3 É interessante ressaltarmos que, como propõe Searle, a Teoria da Verdade como Correspondência faz parte de um "Pano de Fundo cognitivo", de modo que, "a série de afirmações que apresento sobre a realidade e a verdade pode ser tratada como uma teoria, ou mesmo como um conjunto de teorias, mas, quando o Pano de Fundo está funcionando - quando está, por assim dizer, cumprindo seu papel -, não precisamos de uma teoria. Tais pressuposições são anteriores à teoria." (SEARLE, 2000, p. 14).

4 Note-se que ser "objeto de reflexão" não é, necessariamente, o mesmo que ser "opção teórica assumida".

5 As an account of what truth consists in, it holds that the truth of a $p$ consists in a relationship of correspondence between $p$ and the facts. It also holds that whether or not this relationship obtains is itself a fact. It does not consist in anything else. In particular, then, it does not consist in the correspondence of " $p$ corresponds with the facts" to the facts. 
se correspondem, descrevem ou se encaixam à maneira como as coisas realmente são no mundo, e falsas se não o fazem." (2000, p. 22, ênfase nossa). Nesse sentido, é interessante considerar o vínculo que Searle (2000) aponta existir entre o seu Realismo Externo e a Teoria da Verdade como Correspondência. Segundo o autor, o Realismo Externo, isto é, a "concepção" de que o mundo (ou estado de coisas, realidade) existe independentemente de nossas representações a seu respeito, é a base sob a qual se fundamenta essa teoria, de modo que ao assumir a Teoria da Verdade como Correspondência assume-se, consequentemente, o Realismo Externo ${ }^{6}$.

Apesar de amplamente disseminada, a Teoria da Verdade como Correspondência - bem como quaisquer teorias - padece de algumas críticas, sendo a objeção mais usual sistematizada no pensamento de Gottlob Frege. Como se sabe, as críticas do lógico alemão não têm como alvo exclusivo a Teoria da Verdade como Correspondência, uma vez que no entendimento de Frege $(1956,2009)$ existe certa impossibilidade lógica de se definir o que é verdade. Contudo, parece-nos haver uma dedicação especial do autor em estabelecer uma refutação à teoria da correspondência. Nesse sentido, podemos dizer que a mais disseminada objeção fregeana à Teoria da Verdade como Correspondência é o famigerado argumento do regresso ${ }^{7}$.

Em síntese, esse ponto da crítica de Frege (1956) sugere que a teoria da correspondência pressupõe o conceito que está tentando definir. Dito de outro modo, sugere que na enunciação de " $p$ é verdadeiro (ou falso)" há uma pressuposição de que $p$ se ajusta, ou não, ao estado de coisas. Observe: não está sub judice o status (de verdadeiro ou falso) atribuído à proposição $(p)$, mas, antes, pressuposições que ela evoca. Nesse

6 É interessante notar que o contrário não é verdade; isto é, assumir o Realismo Externo não implica necessariamente assumir a Teoria da Verdade por Correspondência (cf. SEARLE, 1995).

7 Devemos fazer duas observações: a primeira refere-se ao fato de que, embora o argumento do regresso seja o ponto principal da crítica de Frege (1957), esse ponto complementa-se com os argumentos (ou partes de argumento) a seguir: a) distinção entre propriedade e relação; e b) distinção entre correspondência perfeita e correspondência parcial (formada a partir de uma reductio ad absurdum da teoria). A segunda observação, por sua vez, diz respeito ao fato de que, tendo em vista que o argumento do regresso é reorganizado por diversos autores, como Dummett (1973), Rickets (2005) e Soames (1998), lidamos aqui apenas com seu aspecto central, ou seja, o ponto que os une à formulação fregeana inicial. 
caso, parece que, para o pensamento fregeano, a dificuldade maior dá-se em virtude de a Teoria da Verdade como Correspondência não conseguir explicar como se chega a $p$, senão recorrendo à pressuposição de uma realidade (um estado de coisas), e ao se recorrer à pressuposição, qualquer status (verdadeiro ou falso) atribuído à proposição não passará da atribuição do status (de verdadeiro ou falso) a uma pressuposição, quando na verdade o status (de verdadeiro ou falso) dado a uma proposição deveria estar baseado na consequência dos fatos.

Diante disso, se a crítica fregeana demonstra - como acredito - a impossibilidade lógica de se chegar a $p$ por outro meio que não seja a pressuposição, tendo a dizer que ainda assim não há elementos teóricos que comprometam de modo consistente a teoria correspondencialista, posto que, como bem coloca Walker, "a teoria da correspondência é uma teoria a respeito daquilo em que consiste a verdade, não uma teoria a respeito daquilo em que consistem os fatos." (1997, p. 318, tradução nossa ${ }^{8}$ ). Os fatos, dentro dessa teoria, apenas são tomados como sendo unidades reais, existentes no tempo e no espaço, independentemente de nossas crenças e experiências. Assim, portanto, se o ponto central do argumento de Frege (1956) parece levantar questionamentos que dizem respeito não apenas à natureza de $p$, mas também à categoria ontológica em que se inscrevem os fatos, a teoria da correspondência, de modo oposto, não se põe a debater tais questões, uma vez que, como já dito, tem como base o Realismo Externo. Nesse sentido, julgamos que a crítica fregeana seria mais relevante se reorientada para esta base em que se ancora a teoria correspondencialista, o Realismo Externo.

$\mathrm{O}$ argumento do regresso tem esse nome devido ao fato de que sua formulação, quando submetida à reductio ad absurdum, aparenta levar-nos a um círculo vicioso sem fim - como defendia Frege (1956). Contudo, se insistirmos na plausibilidade da teoria da correspondência, podemos chegar à mesma conclusão de Ralph Walker, a saber, que, "embora haja uma regressão de algum tipo, não há nada de vicioso a esse respeito, mais do que há algo de vicioso sobre a observação de que, se $p$ é verdadeiro, é verdadeiro que $p$ é verdadeiro, e verdadeiro que é verdadeiro que $p$ é verdadeiro." (1997, p. 318, tradução nossa $\left.{ }^{9}\right)$.

8 The correspondence theory is a theory of what truth consists in, but not a theory of what facts consists in.

$9[\ldots]$ although there is certainly a regress of a kind, there is nothing vicious about 
Deve-se ressaltar que o próprio Walker (1997) apresenta outras três dificuldades à Teoria da Verdade como Correspondência, as quais lhe parecem mais complexas. Podemos resumi-las da seguinte maneira: (1) a teoria da correspondência não apresenta o caráter de uma teoria, antes, apenas de uma mera asserção; (2) a teoria da correspondência concebe um mundo que, de tão independente, torna-se misterioso e inavaliável; e (3) a teoria da correspondência não apresenta uma noção de correspondência que possibilite uma avaliação sobre a correspondência. Com vistas a apresentar resoluções elencadas para a primeira destas dificuldades, $o$ autor traz à baila as "propostas" de (o primeiro) Wittgenstein e de Austin. Contudo, ambas parecem insuficientes para tal fim.

Diante dessas dificuldades apresentadas por Walker (1997) e assumindo que, em alguma medida, a terceira objeção do autor é constituinte da primeira, ou seja, admitindo que a ausência de uma noção de correspondência é um dos fatores que apontam para o caráter não teórico da Teoria da Verdade por Correspondência, resta-nos assumir que (1) e (3) tratam, em última instância, de uma difículdade, não de um fato que refute a hipótese da teoria. Isto é, a dificuldade de representar formalmente a teoria não implica sua negação; pelo contrário, parece-nos confirmar sua complexidade - talvez, um patamar de complexidade muito além daquilo que queremos ou precisamos estruturar sobre ela. Além do mais, essa dificuldade da estruturação formal de uma teoria pode ser vista em outras formulações preciosas, mas igualmente complexas, tais como a searleana Hipótese do Background ${ }^{10}$.

Quanto à segunda dificuldade apresentada por Walker (1997), temos a observação (2) de que esse caráter de independência atribuído ao mundo, que por vezes o torna inavaliável, é muito mais uma propriedade que a teoria da correspondência herda do Realismo Externo - mesmo que este termo tenha sua emergência mais recente - do que da própria teoria per si.

it, any more than there is anything vicious about the observation that if $p$ true, it is true that $p$ is true, and true that it is true that $p$ is true.

10 Searle apresenta sua hipótese de modo mais consistente em Intencionalidade, onde propõe que "o Background é um conjunto de capacidades mentais não-representacionais que permitem a ocorrência de toda representação.” (SEARLE, 2002b, p. 198). Para o filósofo, "não existe vocabulário de primeira ordem para o Background, porque este não tem Intencionalidade. Como pré-condição da Intencionalidade, o Background é tão invisível para a Intencionalidade quanto o olho que vê é invisível a si mesmo." (SEARLE, 2002b, p. 218). 
Desse modo, a veracidade desta dificuldade deve ser redirecionada para a raiz da questão, a saber, a concepção filosófica do Realismo Externo ${ }^{11}$.

Assim, tendo plena consciência de que a Teoria da Verdade como Correspondência, bem como qualquer teoria que se preze, não é unânime, mas dando-nos por satisfeitos em apresentar, ainda que de modo resumido, as contra-objeções ao argumento do regresso, que, por muitos, tem sido considerado a principal objeção a esta teoria, assumimos com Walker que "de fato, é difícil ver como a teoria da correspondência pode conseguir dizer mais do que isso. A ideia de que a estrutura da proposição de algum modo reflete a estrutura do fato é realmente a única sugestão que parece de todo promissora”. (1997, p. 321, tradução nossa $\left.{ }^{12}\right)$.

\title{
3. Sobre o sentido de significado e suas relações com as intenções e convenções ${ }^{13}$
}

Com efeito, alguma concepção de "significado" é pressuposta por toda e qualquer opinião sobre qualquer coisa e uma mudança real de concepção, nesse ponto, envolverá uma mudança em todos os pontos de vista de um pensador coerente.

(OGDEN; RICHARDS, 1976, p. 250).

\begin{abstract}
11 No capítulo inicial de seu Mente, Linguagem e Sociedade, Searle apresenta uma incisiva defesa do Realismo, e aponta: "o realismo externo é a base de outros pontos de vista filosóficos fundamentais frequentemente negados - a teoria referencial do pensamento e da linguagem e a teoria da verdade como correspondência. Pensadores que desejem negar a teoria da verdade como correspondência ou a teoria referencial do pensamento geralmente se sentem pouco à vontade ao terem de aceitar o realismo externo. Muitas vezes, evitam completamente falar no assunto, ou então têm alguma razão mais ou menos sutil para rejeitá-lo. Na verdade, muito poucos pensadores dão um passo a frente e dizem que um mundo real que exista absolutamente, objetivamente e totalmente independente de nós não existe. [...] negações diretas do realismo externo são raras.” (2000, p. 23, ênfase nossa).

12 It is indeed hard to see how the correspondence theory can contrive to say more than this. The ideia that the structure of the proposition somehow reflects the structure of the fact is really the only suggestion that seems at all promising [...]. 13 Tendo em vista que, de modo geral, este trabalho versa sobre as concepções de Searle, faz-se fundamental, destacar a importância de não se confundir "intenção" e "Intenção", bem como "intencionalidade" e "Intencionalidade", as quais estão claramente distinguidas na obra do autor (cf. SEARLE, 2002b).
\end{abstract}


Iniciamos nossas considerações lembrando que, como bem observa Zlatev (2003), o significado é um princípio que diz respeito a toda a vida dos seres vivos e à relação destes com o ambiente em que vivem. Todavia, aqui, nosso olhar estará direcionado ao conceito de significado que concerne especificamente à dimensão linguística do indivíduo humano.

Semelhantemente ao conceito de verdade, os debates acerca do que seria o significado parecem ter a gênese de seu registro também nos escritos de Platão, suscitando, desde então, as mais variadas controvérsias, de modo que um dos poucos consensos a respeito desse conceito é a inexistência de um consenso acerca do significado desse conceito. Nesta direção, é interessante notarmos com Mari que

A própria flutuação terminológica representa dificuldades nesse campo: vacilamos, com alguma frequência, na escolha entre significado e sentido, entre significado e significação, por exemplo, seja por razões conceituais, seja por razões instrumentais quando traduzimos tais termos de uma língua para outra. (1998, p. 21).

No tocante aos nossos interesses para este texto, podemos, inicialmente, elencar algumas perguntas a respeito do significado: o que define o significado de uma sentença? Há limites de significados para uma sentença? Toda sentença comporta qualquer variação de significado? E mais: qual é o papel da intenção do autor na determinação do significado de um texto? A intenção do autor determina o modo como o texto é interpretado? Se, também, a respeito dessas questões não é possível afirmar a existência de um consenso, pode-se, ao menos, indicar dois pontos abordados por Strawson, em seu texto Significado e Verdade, que assumem um status de irrefutáveis, a saber,

que: 1) o significado de uma sentença geralmente depende, de algum modo sistemático, dos significados das palavras que a compõem, e 2) para que uma palavra tenha um determinado significado, é preciso que ela apresente, sistematicamente, uma determinada contribuição aos significados das sentenças em que ocorre. (1982, p. 181).

Em seu trabalho deveras elucidativo para lidarmos com o conceito de significado em que a Teoria dos Atos de Fala está arvorada, Strawson ${ }^{14}$ propõe-se a discorrer sobre "um certo conflito, ou aparente conflito"

14 Embora tenhamos optado pelo texto de Strawson, publicado originalmente em 1970, a perspectiva apresentada pelo autor já está, em alguma medida, colocada na obra Speech Acts, publicada por Searle - como já dito - em 1969. Salientamos, 
(1982, p. 181), a saber, a oposição "entre os teóricos da intenção comunicativa e os teóricos da semântica formal" (1982, p. 181-182). Tendo em vista a abordagem enunciativa da linguagem, podemos dizer que a primeira posição sinaliza para a dimensão da enunciação, e a segunda, para a dimensão do enunciado.

Apontando Austin, Grice e o "segundo" Wittgenstein como "representantes" do primeiro grupo, Strawson afirma que, para os teóricos da intenção comunicativa,

é impossível dar uma explicação adequada do conceito de signifícado sem fazer referência ao fato de que os falantes possuem um certo tipo complexo de intenções dirigidas à audiência. Os significados específicos das palavras e das sentenças são sem dúvida, em grande parte, uma questão de regras e convenções; entretanto, a natureza geral de tais regras e convenções, em última análise, só pode ser entendida se se fizer referência ao conceito de intenção comunicativa. (1982, p. 182).

Por outro lado, tomando Chomsky, Frege e o "primeiro" Wittgenstein como "arautos" do formalismo semântico ${ }^{15}$, Strawson sinaliza que os teóricos do formalismo entendem ser a intenção comunicativa não uma questão essencial, mas sim eventual, haja vista que "o sistema de regras sintáticas e semânticas, em cujo domínio consiste o conhecimento de uma língua - as regras que determinam os significados das sentenças - não é, absolutamente, um sistema de regras para comunicar." (STRAWSON, 1982, p. 182). Assim, para o segundo grupo, o equívoco do primeiro estaria em estruturar a definição de significado sobre uma falsa base, isto é, a ideia de função comunicativa.

De maneira mais sintética, podemos dizer que a abordagem dos teóricos da intenção assume o significado como sendo proveniente de um uso intencional, em circunstâncias específicas e de acordo com determinadas regras e convenções, ao passo que a abordagem dos teóricos do formalismo assume o significado como sendo proveniente da combinação de regras sintáticas e semânticas. Portanto, a raiz de tal contraste encontra-se

ainda, que, como reconhecem os autores, a obra seminal desta perspectiva é o artigo Meaning, publicado por Paul Grice em 1957.

15 A bem da verdade, entendemos como equivocada a inclusão de Chomsky em tal "lista". Afinal, como bem sabemos, no histórico das diversas versões de sua teoria, a semântica (ou o significado) não tem um papel central. Quem deu destaque para a semântica na Teoria Gerativa foram Katz, Bierwich, Weinreich. 
na imensa discrepância entre dois níveis na dimensão do significado: o uso intencional do significado assume o significado como sendo um dado a priori; a dimensão formal coloca o significado como resultado de combinação de regras. Observe-se que, até aqui, a abordagem dos teóricos da intenção não salienta o indivíduo "dono" da intenção comunicativa, antes, o tem apenas como fator subjacente.

Dando prosseguimento a seu texto, Strawson apresenta dois pontos importantes para uma formulação mais robusta de uma teoria da intenção comunicativa. Segundo o autor, faz-se necessário destacar "um conceito primitivo de comunicação (ou intenção comunicativa)" (1982, p. 183) que não pressuponha a noção de significado linguístico. Em seguida, sugere Strawson, faz-se necessária uma explanação que justifique o uso de significado linguístico a partir desse "conceito primitivo de comunicação" (1982, p. 183). Posto isso, o autor sugere algo que parece ser a conclusão mais coerente: sendo os dois pontos anteriores levados a cabo, resta ao teórico da intenção comunicativa assumir o enunciador como um "conceito fundamental na teoria do significado" (STRAWSON, 1982, p. 183). Nessa direção, dizemos tratar-se de uma "conclusão mais coerente" tendo em vista o fato de que, como aponta Strawson, "o que um enunciador significa através de seu enunciado é especificado, evidentemente, através de uma especificação da intenção complexa com que ele produz o enunciado" (1982, p. 183). Dito de outro modo, essa proposta de formulação apresentada por Strawson (1982) desenvolve alguns aspectos importantes da ideia inicial de Grice (1959), induzindo um deslocamento do enunciador, do papel de mero fator subjacente, para um lugar de maior centralidade na teoria do significado à qual se alinham os teóricos da intenção comunicativa.

Diante do exposto, embora não admitamos a possibilidade de se supor uma independência dos teóricos da intenção em relação aos teóricos do formalismo, parece-nos plausível assumir que a caracterização do significado do enunciador esteja para além das possibilidades de conteúdo lexical que eventualmente se estruturam em termos de enunciado. Dizemos, então, numa síntese dos apontamentos de Strawson (cf. 1982, p. 184), que ao menos três pontos devem ser levados em consideração para a caracterização do significado do enunciador: (1) que o enunciador pretende fazer crer ao seu enunciatário que ele, enunciador, acredita numa proposição $p$; (2) que o enunciador pretende que sua intenção inicial esteja clara em seu enunciado, a fim de que seja claramente reconhecida pelo 
enunciatário; e (3) que o enunciador pretende que, satisfeitas as condições (1) e (2), o enunciatário execute determinada ação a partir da enunciação dele, enunciador.

Apresentados esses pontos, que certamente são básicos para a caracterização do significado do enunciador, Strawson afirma que "desde que certas outras condições sobre a intenção do enunciador sejam satisfeitas, pode-se dizer, no sentido relevante, que o enunciador exprime algo através de seu enunciado" (1982, p. 184). Essa afirmação do autor, embora pareça uma conclusão evidente, lança-nos em face da seguinte questão: como, então, depreender a intenção do enunciador? Esta pergunta, por sua vez, lança-nos em face de outra, ainda mais fundamental: o que estamos entendendo, aqui, por intenção?

Começando pelo questionamento mais basilar, até onde sabemos, o termo "intenção" não foi definido de forma teórica - como se costuma fazer com termos-chave de quaisquer teorias. Sua utilização, por Grice (1957) e afins, está relacionada ao entendimento corrente que se tem acerca do referido termo, ou seja, intenção como "propósito que se busca alcançar", "algo que se pretende".

Já no que diz respeito ao primeiro questionamento, isto é, sobre como podemos inferir a intenção do falante, é fundamental atentarmos às observações de Mari:

Uma intenção (ou um complexo de intenções, como prefere Strawson) não é uma propriedade material de um enunciado, na extensão em que atribuímos essa qualificação a propriedades de natureza sintático-semânticas, mas é um modo de ser que acrescentamos a ele, através de algum procedimento que pode expressar uma forma de organização do código. As intenções incorporam-se ao processo enunciativo e não preexistem, de modo independente dos enunciados. A intenção de humilhar o interlocutor pode ser incorporada a muitos dos nossos atos, mas, na qualidade de intenção e não na de convenção, ela não pode ser independente da existência deles, no momento que são proferidos. Para ser detectada, uma intenção requer um custo de processamento mais demorado, por não estar inscrita, de forma transparente, na superfície discursiva de um ato. (1998, p. 40, ênfase nossa.)

Numa síntese das pertinentes colocações de Mari, podemos dizer que qualquer tentativa de depreender as intenções do enunciador passa necessariamente pelo fato de que (a) a intenção do enunciador, em alguma dimensão, precisa estar justificada no próprio enunciado, e (b) tal justificativa no enunciado deve estar relacionada às escolhas lexicais em 
função de um significado que o enunciador imprime ao enunciado. Assim, esses dois aspectos nos conduzem a outro ponto importante no texto de Strawson (1982), a saber, a relação entre o significado comunicacional e o significado linguístico, ou, dito de outro modo, a relação entre o significado do enunciador e o significado do enunciado. Porventura, pode haver independência entre o significado do enunciador e o significado do enunciado? É possível admitir que o comunicacional seja independente do linguístico, ou que o linguístico tenha sua razão de ser, independentemente do comunicacional?

Perguntas como essas certamente demandam uma resposta cuidadosa, e, por vezes, uma explanação longa. Contudo, a fim de não sermos prolixos na explicação dos diferentes pontos, mas também não incorrermos em análises simplórias, apresentaremos, aqui, apenas o ponto que nos parece mais digno de defesa, a saber, a impossibilidade de se pensar o significado do enunciador independentemente do significado do enunciado.

Tendo em vista que o significado linguístico - fator preponderante para os teóricos do formalismo - habitualmente é representado "em termos de regras e convenções semânticas e sintáticas" (STRAWSON, 1982, p. 185), poderia soar um tanto contraditório assumir sua relação com a ideia de significado do enunciador, por ser este um desdobramento da teoria da intenção comunicativa. Contudo, Strawson assume que "regras ou convenções governam as práticas e as atividades humanas que visam a um objetivo" (1982, p. 185), de modo que, no tocante às regras e convenções semânticas e sintáticas, sua finalidade seria exatamente o ato de comunicação, posto que o objetivo do enunciador, a realização de sua intenção comunicativa, se daria mediante a observância de tais regras. Em outros termos, o autor defende que a ideia de significado do enunciador, formulada dentro da teoria da intenção comunicativa, não exclui a noção de significado linguístico pela relação deste com regras e convenções sintáticas e semânticas, antes, o significado linguístico, com todas as suas particularidades, torna-se um fator que corrobora a ideia de significado do enunciador.

Obviamente, essa formulação esbarra no problema da distinção entre as regras; realmente, regras semânticas e sintáticas tendem a serem mais estáveis, formais e objetivas do que regras que regem o processo comunicacional. Contudo, mesmo essas características distintas seriam insuficientes para conter o argumento de Strawson. Primeiramente, porque sabemos, desde Investigações Filosóficas, que a ausência, maior ou 
menor, de regras comuns não desabona o fato de um jogo ser um jogo. $\mathrm{E}$ não vemos motivos para lidarmos diferentemente com o nosso problema. Em segundo lugar, pelo fato de que, embora possamos dizer que somente as regras comunicacionais admitam a dimensão das intenções, a dimensão das convenções parece ser comum a ambas, e é basicamente sobre a noção de convenções que repousa um importante aspecto da argumentação de Strawson (1982).

Segundo o autor, "tudo o que a análise exige é que possamos explicar a noção de convenções de comunicação em termos de noção de comunicação pré-convencional num nível bastante básico." (STRAWSON, 1982, p. 186), o que, de fato, ele faz, ao sugerir que uma intenção comunicativa primária estabeleceu uma comunicação pré-convencional e essa, uma vez posta, constituiu-se um ponto de partida para novas interações, de maneira que, decorrido determinado tempo, esta comunicação que era pré-convencional consolidou-se uma convenção.

Assim, tendo explanado como a noção de comunicação pré-convencional é justificada de acordo com a intenção comunicativa primária, e, com vistas a concluir seus primeiros apontamentos acerca de uma teoria do significado em termos de intenção comunicativa, Strawson (1982) aponta o fato de que, no processo histórico, o caráter estável das intenções alça boa parte delas - talvez, todas - à dimensão das convenções:

As primitivas intenções comunicativas e sucessos de comunicação dão margem ao aparecimento de um sistema de significado convencional limitado, que torna possível o seu próprio enriquecimento e desenvolvimento, que por sua vez torna possível a expansão do pensamento e das necessidades de comunicação até o ponto em que há, novamente, mais pressão sobre os recursos existentes na língua, que, por sua vez, reage a essa pressão... Evidentemente, há um elemento misterioso nisso; mas de qualquer forma, esse elemento também existe no intelecto humano e na criatividade social. (1982, p. 188).

Nesse aspecto, podemos, então, admitir uma relação dupla entre significado e intenções: se por um lado as intenções precedem o significado (o que, observe, é diferente de preexistir independentemente do enunciado), por outro, elas necessitam estar circunscritas àquilo que Gardiner (citado em NERLICH; CLARKE, 2003) chamou de "área de significado". Em outros termos, se inicialmente os significados são instituídos a partir de intenções, em um segundo momento, as intenções necessitam se adequar àquilo que por meio delas se cristalizou, a saber, as convenções. 
Como bem sintetizou Mari,

Ainda que do ponto de vista da produção de um ato, elas possam representar alguma precedência temporal sobre o significado, sabemos que as intenções se submetem a um certo domínio do significado. O leque de intenções que colocamos em jogo num determinado proferimento depende da configuração central do significado que asseguramos para esse proferimento. Assim, intenções e significado regulam-se por um princípio de causalidade, ainda que numa modalidade causal fraca. (1998, p. 47).

De modo similar, Searle nos lembra que

existe um conjunto extremamente complexo de relações entre o significado convencional das sentenças e o significado realizado ou articulado pelo falante. Neste sentido, o significado do falante é primário, tendo em vista que o propósito principal de todo sistema é possibilitar aos falantes comunicar aos ouvintes na execução de atos de fala intencionais. Porém, seria um erro concluir que a comunicação pode ser separada da forma convencional da sentença. Só é possível comunicar, ou até mesmo pensar, pensamentos complexos tendo em conta uma estrutura de significados da sentença. (1994, p. 647, tradução nossa ${ }^{16}$ )

Postas estas colocações acerca da relação entre significado, intenções e convenções, parece-nos, então, que, de fato, há três fatores ao redor dos quais devemos pensar a produção e a compreensão de significado: (a) o sistema, lugar em que majoritariamente repousam as convenções; (b) a relativa autonomia do sujeito, lugar em que as intenções podem estar mais salientes; e (c) o momento sócio-histórico, lugar em que (a) e (b) se defrontam, ora pendendo pra um lado, ora pra outro.

\section{Considerações finais}

Ao longo deste texto, buscamos discorrer sobre os conceitos de "significado" e "verdade" que subjazem à Teoria dos Atos de Fala de orientação searleana. Como ocorre com qualquer texto e, com efeito, com

$16[\ldots]$ there is an extremely complex set of relations between the conventional sentence meaning and the realized or articulated speaker meaning. In one sense, speaker meaning is primary, since the main purpose of the whole system is to enable speakers to communicate to hearers in the performance of intentional speech acts. But it would be a mistake to conclude that communication can be separated altogether from conventional sentence meaning. It is only possible to communicate, or even to think, complex thoughts given a structure of sentence meanings. 
toda a vida, ao escolhermos prolongar uma discussão, escolhemos consequentemente não entrar em outras. Assim, portanto, temos consciência de que determinados assuntos poderiam ter tido uma explanação mais longa e, para alguns desses casos, esperamos que as notas de rodapé, bem como as referências, possam auxiliar o leitor interessado.

Além disso, reconhecemos nossa opção por abordar teoricamente tais conceitos a partir das formulações, que julgamos mais efetivas, de pensadores como Mari, Strawson e Walker. Nessa direção, o discurso direto do próprio John Searle foi retomado apenas com vistas a confirmar a opção do filósofo americano, ou melhor, de sua teoria, por tais noções.

Ao fim e ao cabo, estamos certos que todo o debate linguístico-filosófico acerca da leitura que Searle fez, e faz, de Austin passa, de algum modo, pela concepção de tais noções. E esperamos, portanto, que essa breve concatenação dos pressupostos subjacentes à teoria searleana possa auxiliar futuras investigações, linguísticas ou não, na Teoria dos Atos de Fala•

\section{REFERÊNCIAS}

ARISTÓTELES. Categorias. In: ARISTÓTELES. Órganon: Categorias, Da interpretação, Analíticos anteriores, Analíticos posteriores, Tópicos, Refutações sofísiticas. Tradução, textos adicionais e notas de Edson Bini. Bauru, SP: Edipro, 2005. AUSTIN, John L. (1962). How To Do Things With Words. Cambridge, MA: Harvard University Press.

DUMMETT, Michael. Frege: Philosophy of Language. London, Harper and Row, 1973.

GRICE, Paul H. (1957). Meaning. In: The philosophical review. Cornell University Press, 1957, v. 66, n. 3, p. 377-388. Disponível em: < http://semantics. uchicago.edu/kennedy/classes/f09/semprag1/grice57.pdf $>$.

MARI, Hugo. Os sentidos do significado. Correio Revista da Escola Brasileira de Psicanálise. Belo Horizonte, 1998, v.1, n.18/19, p. 20-49.

NERLICH, Brigitte; CLARKE, David. Blending the past and the present: Conceptual and linguistic integration, 1800-2000. In: DIRVEN, René; PÖRINGS, Ralf. (eds.). Metaphor and metonymy in comparison and contrast. Berlin; New York: Mouton de Gruyter, 2003, p. 555-592.

OGDEN, Charles K.; RICHARDS, Ivor A. O significado de significado: um estudo da influência da linguagem sobre o pensamento e sobre a ciência do simbolismo. Tradução de Álvaro Cabral. 2. ed. Rio de Janeiro: Zahar, 1976. 
PLATÃO. Crátilo. Tradução de Maria José Figueiredo, precedida de estudo introdutório de José Trindade Santos. Lisboa: Instituto Piaget, 2001.

RICKETTS, Thomas. Logic and Truth in Frege. In: Beaney, M.; Reck, E. (Eds.). Gottlob Frege. Critical Assessment of Leading Philosophers. Vol. II. London: Routledge, 2005, p. 121-140.

SEARLE, John R. Expressão e significado: estudos da teoria dos atos de fala. Tradução de Ana Cecília G. A. de Camargo e Ana Luíza Marcondes Garcia. 2. ed. São Paulo: Martins Fontes, 2002a. (Coleção tópicos)

SEARLE, John R. Intencionalidade. Tradução de Júlio Fischer e Tomás Rosa Bueno. Revisão técnica de Ana Cecília G. A. de Camargo e Viviane Veras Costa Pinto. 2. ed. São Paulo: Martins Fontes, 2002b. (Coleção tópicos)

SEARLE, John R. Literary theory and its discontents. In: New Literary History, Vol. 25, No. 3, 1994, pp. 637-667. S.l.: The Johns Hopkins University Press.

SEARLE, John R. Mente, linguagem e sociedade: filosofia no mundo real. Tradução de F. Rangel. Rio de Janeiro: Rocco, 2000. (Ciência Atual).

SEARLE, John R. Os Actos de Fala: um ensaio de Filosofia da Linguagem.Tradução de Carlos Vogt; et al. Coimbra: Almedina, 1981.

SEARLE, John R. Racionalidade e Realismo: o que está em jogo? Tradução de Desidério Murcho. In: Disputatio, 1999, v.7.

SEARLE, John R. The construction of social reality. New York: Free Press, 1995. SOAMES, Scott. Understanding Truth. New York: Oxford University Press, 1998. STRAWSON, Peter. F. Significado e verdade. In: DASCAL, M. (Org.) Fundamentos metodológicos da linguística. Volume III - Semântica. Campinas: Unicamp, 1982, p. 181-212.

WALKER, Ralph C. S. Theories of Truth. In: HALE, Bob; WRIGHT, Crispin. (Orgs.) A Companion to the Philosophy of Language. Oxford: Blackwell, 1997, p. 532-555.

ZLATEV, Jordan. Meaning = Life (+ Culture): An outline of a unified biocultural theory of meaning. Evolution of Communication, 4/2: 2003: 253-296. Disponível em: < http://citeseerx.ist.psu.edu/viewdoc/download?doi=10.1.1.468.963 2\&rep=rep1\&type $=$ pdf $>$. Acesso em: 26 abr. 2018.

Recebido em: 25/07/2019

Aceito em: 10/12/2019 